\title{
Preventing violence in youth sport and physical education: the NOVIS proposal
}

\author{
Francesca Vitali ${ }^{1}$ iD $\cdot$ Salvatore Conte ${ }^{2}$
}

Received: 31 December 2020 / Accepted: 17 July 2021 / Published online: 31 July 2021

(c) The Author(s) 2021

\begin{abstract}
Background Violence in sport, both on and off the field, has been conceived as a main social problem that needs to be prevented.

Aims The purpose of this paper is to present in the 'No Violence in Sport' (NOVIS) project framework, a modular training model, some recommendations and tools that can be implemented in youth sport and physical education (PE) to prevent violence.

Methods A modular training model summarized in a NOVIS methodological guide designed for coaches and PE teachers aimed at raising awareness on preventing violence and developing specific didactic skills to contrast violence is presented. Didactic recommendations to create a mastery (task-involving) motivational climate in youth sport and PE, interactive didactic methodologies and inclusion are the key elements of the modular training model. In addition, some multimedia didactic tools (i.e., sport chart, logbooks, cooperative games, and videos) are also presented.

Conclusions The main aim of the NOVIS project was to develop teaching methodologies and tools focused at preventing violence in youth sport and PE. Future research is needed to implement the modular training model and to test it, evaluating its efficacy, expanding its aims, and adapting it to specific contexts and countries.
\end{abstract}

Keywords Youth sport $\cdot$ Physical education $\cdot$ Violence $\cdot$ Didactic methodologies $\cdot$ Motivational climate

\section{Introduction}

Violence in sport, both on and off the field, has been conceived as a main social problem that needs to be prevented. This is also the perspective of the International Society of Sport Psychology (ISSP), summarized in an official position stand, which is one of the most significant contributions that a team of leading sport psychologists have produced to define, study and mostly important prevent violence in sport [1].

This ISSP official position considers violence in sport as a form of aggression. Aggression can be defined by the infliction of any type of aversive stimulus (e.g. physical, verbal, and behavioural) upon one person by another with the

Francesca Vitali

francesca.vitali@univr.it

1 Department of Neurosciences, Biomedicine and Movement Sciences, University of Verona, Verona, Italy

2 Centro Giovanile di Formazione Sportiva, Prato, Italy specific intent to offend, harm, or injure [2]. Thus, aggression in sport contexts can include a broad number of acts engaged in by athletes, coaches, supporters, and spectators with the specific intent to verbally abuse or physically harm another person.

Violence in sport has been intended by Tenebaum and colleagues [1] as a physical and psychological component of aggression. More precisely, violence in sport has been defined as a "harm-inducing behaviour bearing no direct relationship to the competitive goals of sport, and relates, therefore, to incidents of uncontrolled aggression outside the rules of sport, rather than highly competitive behaviour within the rule boundaries" [3, p. 27]. Indeed, violence in sport correspond to aggressive, illegal, hostile acts that are always intentional. If an athlete has no intention of hurting an opponent and she/he uses legitimate behaviours to reach her/his goals, then that athlete is not engaged in aggressive behaviour but in assertive one. In this case, the difference is the intent: when an athlete has an assertive behaviour, her/ his aim is to impose dominance rather than to injure the opponent [4]. For example, actions such as to tackle in rugby 
or to control in ice hockey can be assertive if the athletes perform them fairly; however, these same actions represent aggression (hostile or instrumental) if the intentions of the athletes are to cause injury [5].

Even supporters and spectators can manifest hostile and instrumental aggression, for example when they verbally offend athletes, coaches, referees or throw objects on the field at an opposing athlete or team: in this case, if the intent is to psychologically offend or physically abuse, it would be considered a form of hostile aggression; on the contrary, if the intent is to unfairly distract the opposing player(s) or to unfairly get an advantage for their team, it would be considered an aggressive instrumental behaviour. Indeed, "those with a legitimate, genuine concern for all levels of sport, from early childhood experiences to age group and master's competition, need to be acutely aware of the negative spectre of aggression and violence. This applies equally to participant behaviour and spectator behaviour" [4, p. 365-366].

\section{Where violence in sport originates?}

Asking where violence in sport is originated represents a hot question. Indeed, there are many reported causes of violence in sport settings: aggression and violence in sport have been interpreted as a result of frustration (e.g. due to losing, underperforming, being injured, and perceiving unfairness in the competition) [6]. Other scholars focused the attention on personal predispositions towards violent actions [7], but in spite of the importance of personality recent research warns against the search of a 'violent-prone personality' and supports an interactive effect between "personal predispositions and situational contingencies in promoting aggressive outcomes" [8, p. 187]. Situational factors play a crucial role in causing violence in sport, and following the interactive hypothesis on its roots, aggression has been primarily intended as a learned behaviour and the result of the interactions between an individual and her/his social environment over time [9].

As sport and society are assumed to mirror each other, the frequency and intensity of aggressive and violent acts in sport take on significant importance: indeed, violent incidents occurred on the field may easily spread out and go far beyond it. Often spread by mass media and amplified by social media, violent behaviours in sport can have larger societal implications and consequences. Furthermore, research findings have also suggested that some supporters like violence in their sports [10-12]. Scholars [13] proposed that the media could sometimes exploit this interest in violence at least in three different ways. A first way is through an over-coverage of such violent acts, images, or sequences that not rarely are replayed over and over again in order to leverage the sensationalism aroused. A second way refers to the use of words, images or sequences to narrate and report on violence in sport that can even glorify it. A third way consists in using past violent acts seen in previous sporting contexts to promote upcoming sport events, building up spectators' expectations towards an event, competition or match exploiting violence in itself.

Sport media play a key role not only in spreading but also in influencing public opinion to interpret a specific event. This is why sport media and sport journalists in particular should be largely aware of the responsibility involved in reporting sport events where violent actions (verbal or physical) have occurred. A good starting point would be, for example, reasoning on the fact that replaying violent images or instances over and over again may amplify their negative effects and the risks of acquisition and emulation, especially by the youngest. Indeed, as it has been assumed that violence in sport could be primarily intended as a learned behaviour [9], then the amplification of violence in sport by the media can cause a downward spiral leading to even more violence [14]. However, the links between media and violence in sport are certainly more complex than this simple cause-and-effect relationship may suggest. In any case, media attention rather than focusing only on the negative cases of violence in sport could turn attention to the many positive aspects that sport can represent, such as fair-play sport actions, skills demonstrations, adaptive and positive strategies employed by athletes and coaches to reach fairly and loyally their goals.

\section{Violence in sport as a moral behaviour}

A couple of years after the publication of the ISSP official position on aggression and violence in sport [1], Kerr [15], who has devoted almost his entire career to these topics, published a detailed commentary on this first document. One main criticism among others that he addressed to the first ISSP official position was that the paper lacked consideration of the role of moral aspects and in particular of the moral nature that both aggression and violence in sport have, which instead appeared to him essential to define this complex phenomenon. Some years later, Kavussanu [16] confirmed Kerr's position: within the setting of a critical review, she presented aggression in sport as a moral behaviour in sport. The author stated that considering the consequences that aggressive behaviours may have on others, aggression and violence in sport should be defined and studied as morally relevant behaviours.

Aggression in sport has been studied mainly using coaches' ratings on athletes' behaviours, athletes' selfreports of their own behaviours, and direct observations. For example, in a study based on coaches' ratings on athletes' behaviours, some basketball coaches were asked to rank and rate the aggressive behaviours of their athletes on the field [17]. In addition, these coaches also were 
required to assess their players' moral reasoning based on the criteria that people usually use to solve moral conflicts, and which were used as indicators of the athletes' moral development [18, 19]. Bredemeier and Shields [17] found out that those athletes whose moral reasoning had been judged less mature by their coaches, showed higher scores of aggressive behaviours; on the contrary, those athletes whose moral reasoning was judged more mature by their coaches, showed the lowest ranks of aggressive behaviours. Coaches' assessments represent a good alternative to athletes' self-reports; a limitation of this method can be that scores may be influenced by various factors such as the level of personal interactions and similarity between coaches and athletes [20].

Other studies have been carried out asking athletes to assess themselves on the frequency of their own aggressive behaviours on the field. For instance, Ryan and colleagues [21] conducted a longitudinal study involving basketball players: they asked them at the beginning and 2 weeks before the end of the sport season to assess the number of times they acted with the intent to induce serious consequences for their opponents during the sport season. The researchers defined six levels of harmful consequences spreading from non-physical intimidation to intentionally pushing an opponent with the purpose of causing permanent disability. At each level the number of actions committed was then multiplied by a coefficient that expressed the severity of each level of actions and at the end the numbers were summed to form a single score of aggressive behaviour self-rated by the athletes. The findings showed that aggressive behaviours reported at the end of the season were predicted by the players' self-assessments collected at the beginning. This study had at least two significant strengths: the longitudinal design and the use of a fairly sophisticated measure of aggression that allowed weight to be differentiated according to severity.

Only few studies on aggression and violence in sport have been carried out using direct observations, such as videotaping of aggressive behaviours. Among them, Kirker and collaborators [22], as previously done by other scholars [21], labelled different types of aggressive (instrumental and hostile) behaviours shown by basketball and ice hockey players, rating them using a severity scale ranging from one to five. Results showed how instrumental aggressive behaviours were two-thirds of the total. In another study [23], the authors coded behaviours that included a penalty for being aggressive (i.e. pushing, fighting, elbowing and diving) using the rules of professional men's ice hockey. Aggressive behaviours were significantly correlated with successful actions (e.g. scoring a goal) when those actions occurred before the aggression. In a research on professional rugby league players, authors used direct observations to code actions such as tackling, hitting on the head, and kicking as intentional aggressive behaviours [24]. Results showed how the highest number of aggressive behaviours occurred in lost games rather than in won ones.

\section{Violence in sport and motivational processes}

The achievement goal theory $[25,26]$ represents an interactionist motivational perspective widely applied both in youth sport [27] and PE at school [28] to study motivational processes and their influence on preventing violence and aggression. This theory gives importance to individual motivational dispositions as well as to situational factors. Perception of competence is a central construct within achievement goal theory. Individuals can use different criteria to judge their own competence in achievement settings. Two major achievement goals (namely, task- and ego-orientation) motivate athletes in sports as well as students in PE settings. Task-oriented persons perceive their own competence and assess their success adopting self-referenced criteria that reflect feelings of effort, personal improvement, progressing in learning and performing one's best. On the contrary, the perception of competence of ego-oriented persons is normatively referenced and their success is a function of social comparison in the attempt of outperforming others, demonstrating greater ability than others with less effort, and performing better than others.

In addition to personal orientations, situational factors (i.e. the motivational climate) also play a crucial role. The social environment created by significant others (e.g. coaches, PE teachers, parents, and peers) can influence the likelihood of whether an individual will be task- or egooriented when participating in youth sport and PE [29]. Perceived motivational climate is defined as a situational variable created by the influential persons. In a mastery (task-involving) climate, the significant others promote learning and cooperation emphasizing improvement, effort, and social relations. They view mistakes as part of the learning process and support people to persist in overcoming difficulties. Conversely, in a performance (ego-involving) climate, the influential persons endorse social comparison and competition fostering social comparison, intra-team competition, and normative-based evaluation. They also tend to criticize athletes or PE students who commit mistakes or underperform.

Compared to ego-oriented peers, high task-oriented athletes and PE students were shown to be more intrinsically motivated, enjoy learning experiences more frequently, feel less boredom, and experience positive activating emotions, such as enjoyment, hope, and pride [30, 31]. In addition, scholars showed how higher ego-oriented female soccer players were more incline to use illegal or unsportspersonlike behaviours in their efforts to succeed in competitions if compared with higher task-oriented peers [32]. Considering task- and ego-orientations and sportspersonship with 
male and female high school basketball players, scholars [33] found that young athletes with moderate to high egoorientation and low task-orientation endorsed unsportspersonlike behaviours and supported aggressive and injurious behaviours intentionally directed towards opponents. Moreover, high ego-orientation was correlated with the young athletes' endorsements of verbal intimidation and injurycausing behaviours that forced an opponent to lose the rest of the sport season. Other authors examined the relationship between goal orientations, perceptions of aggression in sport, and sportspersonship among elite male youth ice hockey players and findings showed that higher task-oriented athletes had higher sportspersonship levels [34].

Research in youth sport and PE has shown that individual's perception of a mastery (task-involving) climate was related to intrinsic motivation, pleasant emotional states, enjoyment, positive attitudes towards the lesson, high perceived competence, interest in sport and PE, satisfaction, adaptive cognitive processes, and lower burnout in youth sport ([27, 35]; see [28] for a review in PE).

Rascle and collaborators [36-39] studied the motivational variables (both at individual and situational level) using the achievement goal theory as a framework [25, 26]: they examined handball and football players' aggressive behaviours by observing and videotaping them in order to code type and frequency of violent actions. Researchers defined aggression in an operational way, such as violation of a rule, instrumental aggression during play or hostile aggression when the ball was not in play [39]. Actions were coded using general categories (i.e. repelling, retaining, hitting, cheating for instrumental aggression, insulting, threatening, making indecent gestures or shoving against opponents, referees, teammates and others for hostile aggression). Results showed that in adolescent male players, the ego-orientation correlated with instrumental aggression: young players with the higher scores of the ego-orientation were more involved in aggressive instrumental actions if compared with the peers with a higher task-orientation [39]. Those athletes involved in higher competitive level showed more instrumental aggression if compared with the lower competitive level players. Moreover, athletes involved in higher competitive levels who perceived a higher performance (egoinvolving) climate created by their coaches showed more aggressive instrumental actions than those who perceived a lower performance (ego-involving) climate [38]. Finally, handball and soccer male players showed more aggressive behaviours compared to female players, and instrumental aggression increased when the competitive level rose, while hostile aggression decreased [36]. Coaches and PE teachers can thus play an important role in enhancing youth athletes' and PE students' motivations and should adopt didactic methodologies and lessons to promote a mastery (taskinvolving) motivational climate.
This paper was written in the so-called "No Violence in Sport' (NOVIS) project framework. The NOVIS was a project co-funded by the Erasmus + Sport program of the European Union. The NOVIS project started in 2019 and brought together within 2 years a multidisciplinary consortium of practitioners and researchers involved in ten organizations (e.g. National Olympic Committees, sport clubs, and national bodies) from seven countries (i.e. Bulgaria, Greece, Italy, The Netherland, Poland, Romania, and Spain) across Europe, coordinated by the Italian Centro Giovanile di Formazione Sportiva in Prato. The main purpose of the NOVIS project was to prevent violence in youth sport and PE. Specific aims were (a) to develop a modular training model aimed at promoting an active participation of stakeholders (i.e. sport clubs and schools) in contrasting and preventing any form of violence, and (b) to create an online website (www.novisport.eu) including multimedia didactic tools (i.e. sport chart, logbooks, cooperative games, and videos) providing recommendations in the topics of preventing violence in youth sport and PE. This paper on the NOVIS project was written in accordance with the Declaration of Helsinki. Furthermore, the NOVIS project was approved by the ethics committee of the University of Verona with anonymity, confidentiality, and allowance to leave the project at any point without consequences being assured for the participants.

\section{Methods}

The cultural and methodological background of the NOVIS project focused on the quality of the training process designed in particular for coaches and PE teachers to enhance their knowledge and skills in contrasting and preventing violence. Indeed, compared to former projects with similar aims (see the 'Io tifo positivo/I Support Pro' project proposed by the Italian association named Comunità Nuova Onlus, http://www.iotifopositivo.it/; the 'ELYS' co-funded by the Erasmus + Sport program of the European Union project), the NOVIS project had twofold purpose: first, to implement a richer and more qualified training process designed for coaches and PE teachers, focused on the contributions coming from the sport psychology, in order to raise their awareness in the topics of contrasting and preventing violence in youth sport and $\mathrm{PE}$; second, to define interactive and inclusive didactic methodologies focused on fostering an even greater active participation from different influential persons (e.g. coaches, PE teachers, parents, sport managers, volunteers, and school deans) distinguishing, where necessary, the specific training aspects for youth sport and PE school contexts. This was also possible because the Italian Centro 
Giovanile di Formazione Sportiva (CGFS) in Prato operated and had an experience that has lasted for many decades in using physical activity in youth sport contexts and PE school settings as an educational environment aimed at the positive, global and holistic psychophysical growth of youth.

\section{Modular training model}

Summarized in a NOVIS methodological guide, a modular training model designed in particular for coaches and PE teachers is presented: its main purpose is twofold, namely (1) to raise the awareness of significant persons (e.g. coaches, PE teachers, but also parents, sport managers, volunteers, and school deans) in contrasting and preventing violence, and (2) to improve their specific didactic skills to tackle and prevent violence. Didactic recommendations to create a mastery (task-involving) motivational climate in youth sport and $\mathrm{PE}$, interactive didactic methodologies and inclusion are the key elements of the modular training model designed in particular for coaches and PE teachers (see Fig. 1).

The different stakeholders and influential persons who operate in the youth sport (e.g., coaches, managers, volunteers, and parents) and in the PE school (e.g., PE teachers, school deans, staff members, and parents) settings can play an important role in enhancing young athletes [35] and PE students' motivations and should adopt teaching methodologies and practices to promote a mastery (task-involving) motivational climate with the specific aim to contrast and prevent violence in youth sport and PE.

An useful didactic approach embedded in the NOVIS modular training model aimed at promoting a mastery (task-involving) motivational climate in youth sport and in PE classroom settings is the TARGET model developed by Epstein [see 25]. TARGET is the acronym of the six different dimensions that form this didactic approach: Tasks, Authority, Recognition, Grouping, Evaluation, and Time. In a high mastery (task-involving) motivational climate youth exercise on different tasks at their own ability level,

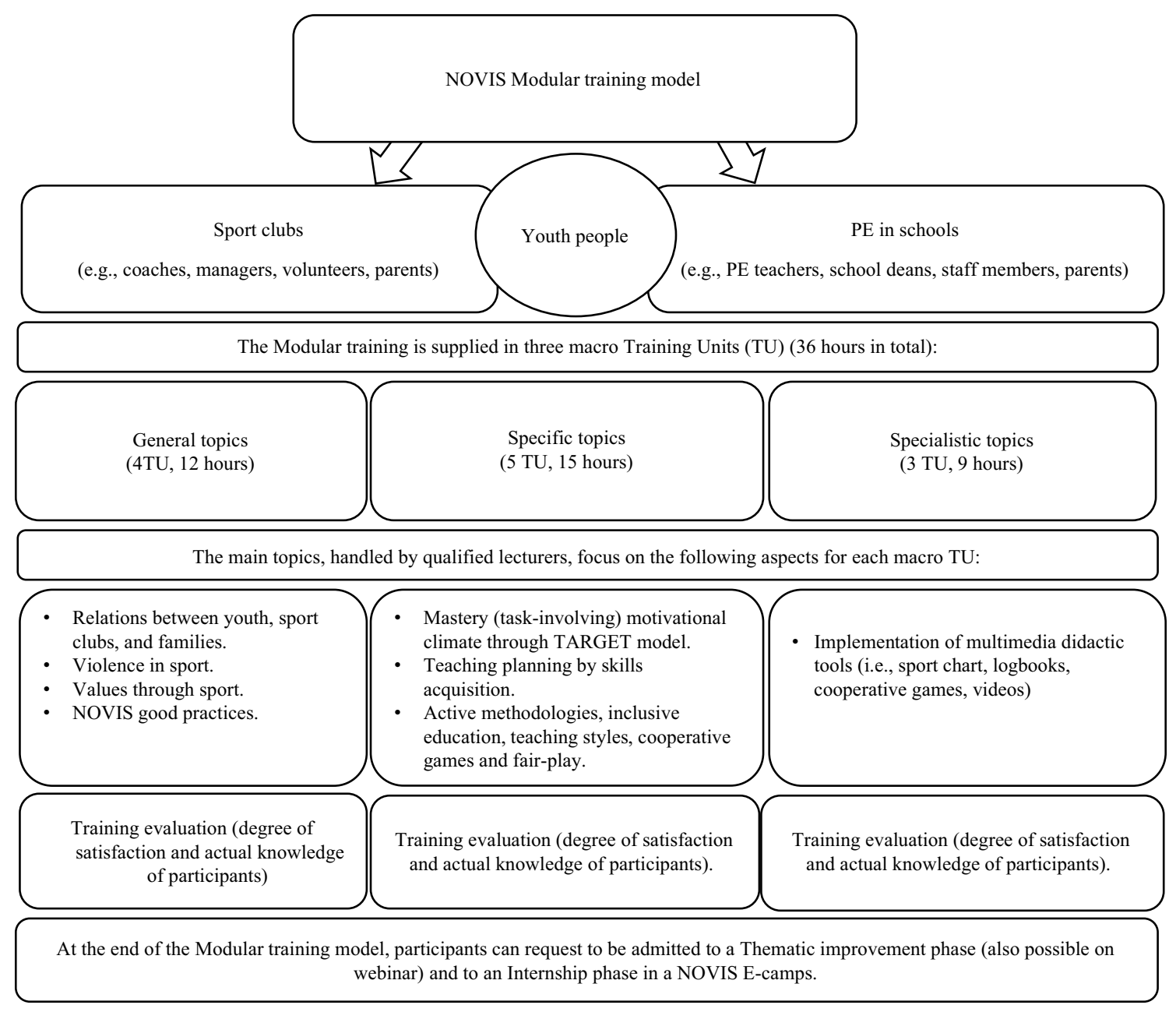

Fig. 1 The NOVIS Modular training model designed for coaches and PE teachers 
are permitted and invited to choose the tasks in which they will participate (i.e. can make choices concerning activities), have all the opportunity to receive rewards, work in mixedability groups, are evaluated on their own objectives, and have flexible time for task completion.

Research in PE has shown that manipulation of TARGET dimensions can influence goal orientations as well as cognitive, behavioural, and affective variables. In a meta-analysis [40], authors synthesized findings from 22 papers describing interventions in which the TARGET model was applied in PE settings. On the whole, results were consistent with achievement goal theory literature showing adaptive outcomes for groups experiencing a mastery (task-involving) motivational climate, and negative outcomes for performance (ego-involving) motivational climate experiences.

In a recent study [41], we addressed emotional issues associated with PE interventions, examining the effects of manipulating the motivational climate on pupils' climate perception, also taking into account the effect of individual goal orientation and the effects of the mastery or performance (task- or ego-involving) climate on adolescent students' psycho-bio-social states. Findings showed that a clear-cut mastery (task-involving) motivational climate or performance (ego-involving) motivational climate influenced PE students' climate perception, thereby overriding the individual's dispositional goal orientation. In particular, the ego-involved group reported lower post-test scores in the perceived mastery (task-involving) motivational climate and higher scores in the performance (ego-involving) motivational climate. Regarding the emotional consequences of a specific motivational climate, our results were in line with previous findings in PE, where researchers have used the achievement goal theory as a framework to examine different motivational climate interventions [42-44]. From an applied perspective, these findings underlined the need for PE teachers to carefully consider the way in which they structure lessons because adopting a mastery (task-involving) motivational climate can have a critical and positive effect in enhancing PE students' motivations.

The TARGET approach, aimed at providing young athletes and PE students with successful learning experiences through the monitoring of individual progress and the establishment of challenging and diverse goals, can be considered an interactive didactic methodology. Indeed, the "authority" is shared between adults and pupils, and the young athletes and PE students can set the rules for each team, group or class together with the coach or the PE teacher. Furthermore, the "evaluation" and the "recognition" are given on an individual basis and through an interactive relationship between young athletes and coaches and between PE students and teachers: bot in youth sport and PE pupils are rewarded for their personal development, efforts and achievements.
The interactive didactic methodologies proposed by the modular training model are aimed to enhance awareness and promote exchange of experiences, sympathizing with a relationship-based working where the focus is on the people involved and the meaning of what is done both individually and as a group. The interactive involvement of the different persons gathered together in the training makes it possible to deepen some concepts and meanings that are attributed to fair play, respect for rules and persons, legality in sport.

In youth sport and in PE the didactic approach that had mostly influenced young athletes and PE students to respect all forms of differences (e.g. based on age, disability, ethnic origin, gender, and sexual orientation) among people and to prevent any form of violence upon them is inclusion [45]. Youth sport and PE, if intentionally used by adults for this purpose, can be potential educative settings to include individuals and educate them to respect all forms of differences that can characterize people. Therefore, the necessity to consider inclusion of all individuals in youth sport and PE is a priority to achieve and a pillar of the modular training model summarized in the NOVIS methodological guide. An inclusive teaching context in youth sport and in PE aims to enhance the respect for all forms of differences and gives value to the skills each young athlete or PE student has, recognizing the differences and not hiding them, encouraging the mutual learning of skills (e.g. physical, sport-specific, life skills) while respecting the abilities, uniqueness, and potential of each person [45, 46]. Some disability sport psychology studies have shown that inclusion is a teaching approach perceived in a positive way also by young athletes and PE students without disabilities [47-50]. Indeed, several studies have shown that when youth sport and PE are truly inclusive settings, motor learning and skills acquisition of pupils without disabilities can even be facilitated and improved [51, 52].

\section{Multimedia didactic tools}

Some multimedia didactic tools (i.e. sport chart, logbooks, cooperative games, videos) are also provided within the NOVIS project and can be downloaded from the resource center' pages on the NOVIS website (https://www.novisport. eu/resource-center/).

The sport chart is a tool that youth sport coaches and PE teachers can implement to find simple definitions to use with pupils to present and discuss values of sport and PE and to define and share the meanings of key concepts (i.e. enjoyment, inclusion, fairness, emotions, good relationships, citizenship, trust, commitment, sports culture, health, education in sport and PE) not always of easy understanding for youth. The sport chart has been created as an European implementation of the previous sport chart created within the 'Io tifo positivo/I Support Pro' project proposed by the 
Italian association named Comunità Nuova Onlus. The initial document has been created thanks to the involvement of schools and subsequently addressed to sport clubs. The sport chart proposes simple definitions of key concepts and requires the interlocutor (i.e. coach, manager, volunteer, parent, PE teacher, school dean or any adult involved) to take real responsibility for her/his role.

The logbooks can be proposed by coaches and PE teachers and filled by young sport players and supporters and by PE students as a diary to write and work on over time: this tool may help pupils reflecting on their own experiences and understanding key concepts applied to sport and PE. The logbook is a tool that allows to collect experiences on the topic of prevention of violence in sport. The logbooks present a section dedicated to young athletes or PE students and another dedicated to parents: used as a diary, can collect reflections and emotions and connect children and youngsters with adults. Thoughts, ideas, drawings, photos, newspaper clippings can be filled in the logbook.

A long list of different cooperative games had been identified and made available for coaches and PE teachers to structure their activities and lessons. These games use cooperation, defined as "a social process through which performance is evaluated and rewarded in terms of collective commitment and motivation on which a group of people work together to achieve a common specific goal" [53, p. 79]. Orlick, a Canadian sport psychologist, expert of cooperative games and sports, explained how the structure of a game or sport can greatly influence the predominant behavioural predisposition (e.g. competitive vs. cooperative, individualistic vs. collective) of a pupil [54]. In this sense, competition and cooperation represent two complementary behavioural processes with different potential interactions that coaches and PE teachers can take into account with the aim to support young athletes and PE students at expressing their potential and achieving their goals in youth sport and in PE.

Finally, several videos had been prepared within the NOVIS project to communicate and spread clear and positive messages, images, and sequences useful to integrate activities and lessons for coaches and PE teachers with the aim to help them contrasting and preventing violence in youth sport and PE. Videos can lead to positive conditions to activate reflections on violence in sport and convey contents, messages and collaborative conditions to give the chance to disseminate the values of non-violence in sport.

\section{Conclusions}

The main aim of the NOVIS project was to develop teaching and didactic methodologies, recommendations and tools focused at contrasting and preventing violence in youth sport and PE. Violence in sport, both on and off the field, has been conceived as a main social problem that needs to be prevented. The purpose of this paper was to present in the NOVIS framework, a modular training model, some recommendations and tools that can be implemented in youth sport and PE to prevent violence. The modular training model summarized in the NOVIS methodological guide was designed in particular for youth sport coaches and PE teachers to raise awareness on preventing violence and developing specific didactic skills to contrast it. Didactic recommendations to promote a mastery (task-involving) motivational climate in youth sport and PE, to adopt interactive didactic methodologies, and to enhance inclusion were the key elements of the modular training model. In addition, some multimedia didactic tools (i.e. sport chart, logbooks, cooperative games, and videos) were presented.

This paper pointed out some potential spin-offs and recommendations for youth sport coaches and PE teachers, but also for parents, sport managers, school deans, volunteers, supporters, spectators who think that physical activity (i.e. youth sport and PE) can serve intentionally as educative contexts to contrast and prevent different forms of violence. In conclusion, a first recommendation concerned the importance of defining violence in sport and becoming even more aware of its different, possible and wide forms. A second recommendation referred to the priority of raising awareness on any forms of violence and promoting youth sport and $\mathrm{PE}$ as potential educative contexts to prevent it. A third recommendation related to the necessity of improving coaches' and PE teachers' didactic skills focused to create specific contexts in youth sport settings and PE classrooms which can be truly effective in preventive different forms of violence.

Future research is needed to implement the modular training model proposed within the NOVIS project and to test it, evaluating its efficacy, expanding its aims, correcting its limitations, and adapting it to specific contexts and countries.

Acknowledgements This paper was written in the NOVIS framework.

Funding Open access funding provided by Università degli Studi di Verona within the CRUI-CARE Agreement.

\section{Declarations}

Conflict of interest Francesca Vitali and Salvatore Conte declare they have no conflict of interest.

Ethical approval and Informed consent This paper on the NOVIS project was written in accordance with the Declaration of Helsinki. Furthermore, the NOVIS project was approved by the ethics committee of the University of Verona with anonymity, confidentiality, and allowance to leave the project at any point without consequences being assured for the participants. 
Open Access This article is licensed under a Creative Commons Attribution 4.0 International License, which permits use, sharing, adaptation, distribution and reproduction in any medium or format, as long as you give appropriate credit to the original author(s) and the source, provide a link to the Creative Commons licence, and indicate if changes were made. The images or other third party material in this article are included in the article's Creative Commons licence, unless indicated otherwise in a credit line to the material. If material is not included in the article's Creative Commons licence and your intended use is not permitted by statutory regulation or exceeds the permitted use, you will need to obtain permission directly from the copyright holder. To view a copy of this licence, visit http://creativecommons.org/licenses/by/4.0/.

\section{References}

1. Tenebaum G, Stewart E, Singer R, Duda J (1997) Aggression and violence in sport: an ISSP position stand. J Sports Med Phys Fit 37:146-150

2. LeUnes ID, Nation JR (1989) Sport psychology: an introduction. Nelson-Hall, Chicago

3. Terry PC, Jackson JJ (1985) The determinants and control of violence in sport. Quest 3:27-37

4. Thirer J (1993) Aggression. In: Singer RN, Murphey M, Tennant LK (eds) Handbook of research on sport psychology. Macmillan, pp 365-378

5. Anshel MH (1990) Sportpsychology: from theory to practice. Gorsuch Scarisbrick, Scottsdale

6. Dollard J, Doob L, Miller N, Mowrer O, Sears R (1939) Frustration and aggression. Yale University Press, New Haven

7. Berkowitz L (1969) Roots of aggression: a re-examination of the frustration-aggression hypothesis. Atherton, New York

8. Walters GD (2000) Disposed to aggress? In search of the violenceprone personality. Aggress Viol Behav 5:177-190

9. Bandura A (1997) Self-efficacy: the exercise of control. Freeman, New York

10. Comisky PW, Bryant J, Zillman D (1977) Commentary as a substitute for action. J Commun 27:150-153

11. Bryant J, Comisky PW, Zillman D (1981) The appeal of roughand-tumble play in televised football. Commun Q 29:256-262

12. Bryant J, Brown D, Comisky PW, Zillman D (1982) Sports and spectators: commentary and appreciation. J Commun 32:109-119

13. Bryant J, Zillman D (1983) Sports violence and the media. In: Goldstein G (ed) Sport violence. Springer, New York, pp 195-211

14. Geen RG (1990) Human aggression. Open University Press, Buckingham

15. Kerr JH (1999) The role of aggression and violence in sport: a rejoinder to the ISSP position stand. Sport Psychol 13:83-88

16. Kavussanu M (2008) Moral behaviour in sport: a critical review of the literature. Int Rev Sport Exerc Psychol 1:124-138

17. Bredemeier BJ, Shields DL (1984) The utility of moral stage analysis in the investigation of athletic aggression. Sociol Sport J 1:138-149

18. Bredemeier BJ (1985) Moral reasoning: the perceived legitimacy of intentionally injurious sports acts. J Sport Psychol 7:110-124

19. Kohlberg L (1984) Essays on moral development. In: Kohlberg L (ed) The psychology of moral development, 2nd edn. Harper \& Row, San Francisco

20. Bredemeier BJL, Shields DL (1998) Moral assessment in sport psychology. In: Duda JL (ed) Advances in sport and exercise psychology measurement. Fitness Information Technology, Morgantown, pp 257-276

21. Ryan MK, Williams JM, Wimer B (1990) Athletic aggression: perceived legitimacy and behavioral intentions in girls' high school basketball. J Sport Exerc Psychol 12:48-55

22. Kirker B, Tenenbaum G, Mattson J (2000) An investigation of the dynamics of aggression: direct observations in ice hockey and basketball. Res Q Exerc Sport 71:373-386

23. Sheldon JP, Aimar CM (2001) The role aggression plays in successful and unsuccessful ice hockey behaviors. Res Q Exerc Sport 72:304-309

24. Jones MV, Bray SR, Olivier S (2005) Game location and aggression in rugby league. J Sport Sci 23:387-393

25. Ames C (1992) Achievement goals, motivational climate, and motivational processes. In: Roberts GC (ed) Motivation in sport and exercise. Human Kinetics, Champaign, pp 161-176

26. Nicholls JG (1984) Achievement motivation: conceptions of ability, subjective experience, task choice, and performance. Psychol Rev 91:328-346

27. Duda JL (2001) Achievement goal research in sport: pushing the boundaries and clarifying some misunderstandings. In: Roberts GC (ed) Advances in motivation in sport and exercise. Human Kinetics, Champaign, pp 129-182

28. Biddle SJH (2001) Enhancing motivation in physical education. In: Roberts GC (ed) Advances in motivation in sport and exercise. Human Kinetics, Champaign, pp 101-127

29. Roberts GC, Treasure DC, Conroy DE (2007) Understanding the dynamics of motivation in sport and physical activity: an achievement goal interpretation. In: Tenenbaum G, Eklund R (eds) Handbook of sport psychology, 3rd edn. Wiley, New York, pp 3-30

30. Duda JL (1996) Maximizing motivation in sport and physical education among children and adolescents: the case for greater task involvement. Quest 48:290-302

31. Mouratidis A, Vansteenkiste M, Lens W, Vanden Auweele Y (2009) Beyond positive and negative affect: achievement goals and discrete emotions in the elementary physical education classroom. Psychol Sport Exerc 10:336-343

32. Stephens DE, Bredemeir BJL (1996) Moral atmosphere and judgments about aggression in girls' soccer: relationships among moral and motivational variables. J Sport Exerc Psychol $18: 158-173$

33. Duda JL, Olson LK, Templin TJ (1991) The relationship of task and ego orientation to sportsmanship attitudes and the perceived legitimacy of injurious acts. Res Q Exerc Sport 62(79):87

34. Dunn JGH, Dunn JC (1999) Goal orientations, perceptions of aggression, and sportspersonship in elite male youth ice hockey players. Sport Psychol 13:183-200

35. Vitali F, Bortoli L, Bertinato L, Robazza C, Schena F (2015) Motivational climate, resilience, and burnout in youth sport. Sport Sci Health 11:103-108

36. Coulomb-Cabagno G, Rascle O (2006) Team sports players' observed aggression as a function of gender, competitive level, and sport type. J Appl Soc Psychol 36:1980-2000

37. Rascle O, Coulomb G (2003) Aggression in youth handball: relationships between goal orientations and induced motivational context. Soc Behav Person 31:21-34

38. Rascle O, Coulomb-Cabagno G, Delsarte A (2005) Perceived motivational climate and observed aggression as a function of competitive level in youth male French handball. J Sport Behav 28:51-67

39. Rascle O, Coulomb G, Pfister R (1998) Aggression and goal orientations in handball: influence of institutional sport context. Percept Mot Skills 86:1347-1360 
40. Braithwaite R, Spray CM, Warburton VE (2011) Motivational climate interventions in physical education: a meta-analysis. Psychol Sport Exerc 12:628-638

41. Bortoli L, Bertollo M, Vitali F, Filho E, Robazza C (2015) The effects of motivational climate interventions on psychobiosocial states in high school physical education. Res Q Exerc Sport 86:196-204

42. Barkoukis V, Tsorbatzoudis H, Grouios G (2008) Manipulation of motivational climate in physical education: effects of a sevenmonth intervention. Eur Phys Educ Rev 14:367-387

43. Escartí A, Gutiérrez M (2001) Influence of the motivational climate in physical education on the intention to practice physical activity or sport. Eur J Sport Sci 1:1-12

44. Weigand DA, Burton S (2002) Manipulating achievement motivation in physical education by manipulating the motivational climate. Eur J Sport Sci 2:1-14

45. Lieberman LJ, Houston-Wilson C (2002) Strategies for inclusion. Human Kinetics, Champaign

46. Block ME (2000) Including children with disabilities in regular physical education: a guide for practitioners. County Public Schools, Baltimore

47. Archie VW, Sherrill C (1989) Attitudes toward handicapped peers of mainstreamed and non-mainstreamed children in physical education. Percept Motor Skills 69:319-322

48. Block ME, Zeman R (1996) Including students with disabilities in regular physical education: effects on nondisabled children. Adapt Phys Act Q 13:38-49
49. Martin JJ, Vitali F (2011) Social identity implications for active individuals with physical disabilities. In: Wearing M (ed) Social identity. Nova Science Publishers, London, pp 163-173

50. Martin JJ, Vitali F, Leigh Whalen L (2014) Individuals with disabilities. In: Papaioannou A, Hackfort D (eds) Routledge companion to sport and exercise psychology. Global perspectives and fundamental concepts. Taylor \& Francis Publishers, London, pp 105-118

51. Obrusníková I, Válková H, Block M (2003) Impact of inclusion in general physical education on students without disabilities. Adapt Phys Act Q 20:230-245

52. Vogler EW, Koranda R (2000) Including a child with severe cerebral palsy in physical education: a case study. Adapt Phys Act Q 9:316-329

53. Coakley J (1994) Sport in society: issues and controversies, 4th edn. Times Mirror Mosby College, St. Louis

54. Orlick T (1978) The cooperative sports and games book. Pantheon, New York

Publisher's Note Springer Nature remains neutral with regard to jurisdictional claims in published maps and institutional affiliations. 